Research Article

\title{
Analysis of the Effect of Whirl on Drillstring Fatigue
}

\author{
Chong Wang $\mathbb{D}^{1},{ }^{1}$ Xufeng $\mathrm{Li}^{2}{ }^{2}$ Yafeng Li, ${ }^{1}$ Wenhao $\mathrm{Xu},{ }^{2}$ and Wuyi Liao ${ }^{1}$ \\ ${ }^{1}$ Key Laboratory of Deep Geodrilling Technology, Ministry of Land and Resources, Beijing 100083, China \\ ${ }^{2}$ Shengli Petroleum Engineering Co. Ltd., Drilling Technology Research Institute, Dongying, China \\ Correspondence should be addressed to Chong Wang; wdlc282@163.com
}

Received 18 October 2020; Revised 11 December 2020; Accepted 22 January 2021; Published 23 February 2021

Academic Editor: Roberto Nascimbene

Copyright (C) 2021 Chong Wang et al. This is an open access article distributed under the Creative Commons Attribution License, which permits unrestricted use, distribution, and reproduction in any medium, provided the original work is properly cited.

There are many kinds of vibration forms of drillstring in petroleum drilling. Whirl is one of the main vibration modes when drilling tools are drilling, and it is also the main reason of fatigue failure of the drillstring. In this paper, the causes of drillstring whirl are analyzed. The results show that the speed of rotation (RPM) is a major factor that affects the severity of the whirl. The greater the speed of rotation, the more intense the whirl. The whirl of the drillstring will produce bending stress. The severity of the whirl of the drillstring is the main factor affecting the bending stress. The increase of RPM and weight on bit (WOB) will lead to the increase of bending stress. The RPM has a great influence on the bending stress. Given the complex stress condition of drillstring, the calculation model of safety factor is established. The bending stress and safety factor are calculated under the different WOB and RPM. The relationship between dynamic bending stress and the safety factor of drilling tools is analyzed. Bending stress has great influence on the safety factor of drillstring. The variation trend of safety factor is opposite to that of bending stress caused by whirl. It provides a theoretical reference for the optimization of drilling tools in drilling engineering construction.

\section{Introduction}

During the drilling process of the oil drillstring, the working environment is harsh, and its force is extremely complicated. The drilling tool vibrates continuously during drilling, which can easily cause fatigue failure due to the influence of alternating stress and impact load caused by vibration. Research shows that drill tool vibration and alternating stress are the main reasons for drill bit and drill tool assembly damage and drilling performance declination [1-3]. Statistics show that more than $50 \%$ of drillstring failures are caused by fatigue. Drilling dynamics and vibration have become a research focus in oil-and-gas industry because of drilling inefficiency and drilling performance declination [4].

The lower part of the drilling rig is the drillstring, which is normally composed of three parts: bottom hole assembly (BHA), high weighted drill pipe, and drill pipe [5]. In the process of drilling in complex geological conditions, the upper and lower sections of the drillstring continuously bear tensile, compressive, bending, and torsional stresses. These will lead to the failure of drilling tools, decrease of ROP, and increase of the extra time required to replace the failed tools
[6]. Millheim and Apostal combined the finite element method with computer technology and simulated the twodimensional stress and deformation of the drillstring and then gradually expanded the research content to the threedimensional dynamic analysis [7]. Tucker and Wang established the dynamic equation of the drill pipe system. Given the interaction between the drill bit and the rock, the axial vibration, lateral vibration, torsional vibration, and stick-slip vibration were analyzed [8]. Knight and Brennan found that any stress concentration combined with a moderate bore eccentricity will result in a significant reduction in the fatigue life of the drill pipe under bending loads [9]. Wang et al. collected many cases of drillstring failure and observed that the fatigue failure of the drillstring is mostly caused by the extra-large tensile or compressive stress [10]. The large and complex dynamic stress during drilling leads to excessive vibration and premature failure of drillstring [11]. Jiang proposed a model to calculate bending stress and life of drillstring. Based on Rubinsky theory, the bending model is established and this model considers the fatigue life. The bending stress of dangerous parts of drillstring is obtained by this model [12]. Heisig and Neubert 
studied the impact between drillstring and borehole wall and deduced the lateral vibration model of drillstring [13].

The downhole vibration of the drilling tool mainly contains axial vibration, lateral vibration, and torsional vibration, which is an important cause of precocious failure of drilling $[14,15]$. The lateral vibration has always been the main cause of the fatigue failure of the bottom hole assembly [16]. Mitchell and Allen analyzed and studied the movement of BHA with different degrees of freedom based on the finite element principle, considered the borehole trajectory, WOB, and other variables, and determined that the lateral vibration can seriously harm the safety of drilling tools [17]. A large amount of MWD data shows that BHA has severe lateral vibration, which is far more harmful than axial and torsional vibration $[18,19]$. Johnson found that the whirl of the drill bit is the main reason for the damage of the PDC bit. Through the improvement of bit, the possibility of bit whirl is reduced. Field practice shows that this method can reduce the damage of the bit and increase the ROP, which shows the damage of whirl to the drill tool indirectly [20]. Ghasemloonia et al. used the variation of drilling parameters (such as RPM and bit weight) to predict the change of vibration type of drilling tool. At the same time, they analyzed the effects of mud damping, driving torque, and axial load on the vibration of drilling tools. They found that coupled nonlinear axial vibration, lateral vibration, and lateral instability can cause damage to the drillstring [21].

There is a positive correlation between drillstring vibration and internal stress. The internal stress is calculated by the model, and then the reliability of BHA is evaluated according to dynamic stress level [22]. It is an effective measure to reduce the possibility of vibration and downhole premature failure operating the drillstring above or below the critical speed and conducting predrilling and real-time analysis of drillstring dynamics $[23,24]$. Although these studies show that the whirl of the drilling tool has a greater impact on the safety of the drilling tool, the causes of the fatigue failure of the drilling tool are rarely discussed from the perspective of the force of the drillstring. The stress that the downhole drilling tool bears is extremely complex, and different types of stress play different roles in the fatigue failure process of the drilling tool. Therefore, it is very necessary to explore the influence of different types of stresses on the safety during whirl, when considering the fatigue conditions of drilling tools.

In this paper, the research mainly focuses on the impact of bending stress produced by whirl, which has a great effect on the safety of drillstring. Firstly, we have studied the related principles of whirl and analyzed the correlation between the whirl severity and the RPM or WOB. Then the bending stress was calculated in the process of drilling tool whirling. Then, we calculated the alternating stress and fatigue safety factor of drilling tool and studied the correlation between stress and safety factor.

\section{Modeling and Methods}

2.1. Whirl Model of Drillstring. The drillstring not only rotates during drilling but also generates whirl under the conditions of the interaction between the drilling tool and the well wall. The large alternating bending stress caused by eccentric reversal and working load often causes fatigue failure of the drillstring in a deviated well. The probability of pure rolling backward whirl is much higher than that of forward whirl during PDC bit drilling.

Figure 1 shows state and deformation of drillstring on circumstances of whirl. When the drill pipe rolls along the well wall (without sliding backward whirl), there exists the following relationship between the whirl angular velocity and the angular velocity [25].

$$
\omega_{P}=-\frac{\omega_{r} D_{o}}{D_{w}-D_{o}},
$$

where $\omega_{p}$ is the whirl angular velocity and $\omega_{r}$ is the angular velocity. $D_{w}$ is the borehole diameter. $D_{o}$ is the drillstring diameter.

According to equation (1), when the drilling tool is rolling purely along the borehole wall, the whirling angular velocity of the drilling tool is proportional to the rotation. The RPM of the drilling tool will affect not only the whirl speed of the drilling tool but also the frequency of contact between the drilling tool and the borehole wall. When the drillstring whirls regularly, the trajectory of a point on the outer edge of BHA along the wellbore can be described by geometric method, and the trajectory and velocity of point $P$ of the drilling tool can be analyzed by using equation (2) [26].

Assume that $x$ is the $X$ coordinate of point $P, y$ is the $Y$ coordinate of point $P, V_{x}$ is the transverse velocity, $V_{y}$ is the longitudinal velocity, and $V_{s}$ is the velocity. So, the model can be established by trajectory and velocity related in point $P$. The angular velocity is negative in the Cartesian coordinate system.

(1) Trajectory model of point $P$ is as follows:

$$
\left\{\begin{array}{l}
x=\cos \left(\omega_{p} t\right) \frac{\left(D_{w}-D_{o}\right)}{2}+\cos \left(\omega_{r} t\right) \frac{D_{o}}{2}, \\
y=\sin \left(\omega_{p} t\right) \frac{\left(D_{w}-D_{o}\right)}{2}+\sin \left(\omega_{r} t\right) \frac{D_{o}}{2} .
\end{array}\right.
$$

(2) Velocity model of point $P$ is as follows:

$$
\left\{\begin{array}{l}
V_{x}=-\omega_{p} \sin \left(\omega_{p} t\right) \frac{\left(D_{w}-D_{o}\right)}{2}-\omega_{r} \sin \left(\omega_{r} t\right) \frac{D_{o}}{2}, \\
V_{y}=\omega_{p} \cos \left(\omega_{p} t\right) \frac{\left(D_{w}-D_{o}\right)}{2}+\omega_{r} \cos \left(\omega_{r} t\right) \frac{D_{o}}{2}, \\
V_{s}=\sqrt{V_{x}^{2}+V_{y}^{2}} .
\end{array}\right.
$$

2.2. Bending Stress while Drillstring Whirling. Drill collar fatigue failure often occurs during drilling. After analysis, it is found that the fatigue failure of drill collar is caused by the cyclic bending stress caused by severe downhole vibration [27]. The NOV-Grant-Prideco analysis data obtained from the fatigue test of drilling tools show that repeated bending is one of the causes of drillstring fatigue. 


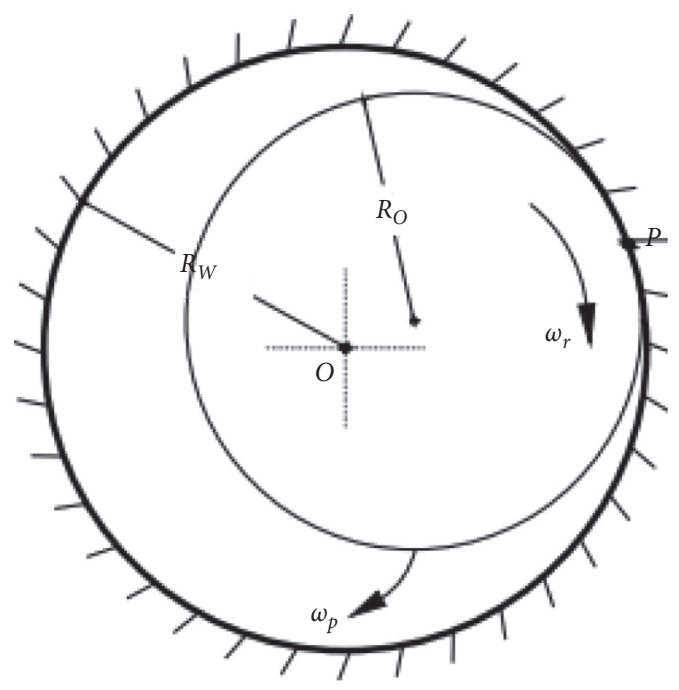

(a)

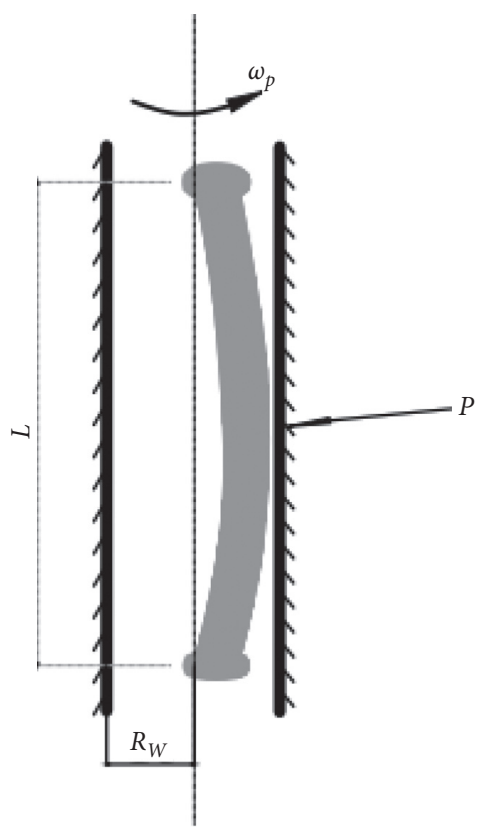

(b)

FIgURE 1: Schematic diagram of whirl. $R_{w}=$ borehole radius, $R_{o}=$ drillstring radius, $\omega_{r}=$ rotation velocity, and $\omega_{p}=$ whirl angular velocity.

When drilling in the well, due to the action of centrifugal force, the drilling tool deflects and constantly contacts with the borehole wall. Due to the frictional force and axial load caused by contact with the borehole wall, the drilling tool can easily produce counterclockwise reversal speed. As long as the friction is high enough, the drilling tool can produce reverse motion at any speed [28]. The rapid change of the bending moment on this moving drill pipe produces high amplitude bending stress cycles, which leads to reduced drilling efficiency, borehole wear, and premature failure of the drilling tool [29].

According to the research, the bending stress of the drillstring is actually caused by the propagation of selfexcited transverse vibration of multiple fulcrums (drill pipe joints) along the drillstring. Taking a single drillstring as the research object, the maximum bending stress in backward whirling is obtained. A single drillstring with longitudinal force under rotation and backward whirl conditions can be regarded as a simply supported beam model in a certain state, as shown in the figure below [30]. Figure 2 shows whirl, stress distribution, and strain of drillstring.

It is assumed that the maximum deflection of the center point of a single drilling tool is $\delta_{\text {maxpl }}$. Bending stress consists of two parts: one is the centrifugal force generated by the rotation of drillstring, and the other is the bending stress caused by the vibration of drilling tool during drilling. When the drillstring is applied with longitudinal load, the maximum bending deflection of the pipe is as follows:

$$
\delta_{\max p l}=\frac{4}{\pi} \frac{\gamma_{s} \cdot A \cdot R \cdot \omega_{P}^{2} \cdot L_{1}^{4}}{\left[\pi^{4} E I g-\gamma_{s} A\left(\omega_{P}+\omega_{r}\right)^{2} L_{1}^{4}\right] \pm \pi^{2} P L_{1}^{2} g},
$$

where $E$ is Young's modulus, $P$ is the longitudinal load, $I$ is the inertia moment, $L_{1}$ is the length of a drilling tool, $\gamma_{s}$ is the unit weight of drillstring, $A$ is the cross-sectional area, and $R$ can be obtained by $R=\left(D_{w}-D_{o}\right) / 2$.

Maximum bending moment $M_{\text {maxpl }}$ is as follows:

$$
\begin{aligned}
M_{\text {maxpl }}= & \frac{\gamma_{s} A R \omega_{P}^{2} L_{1}^{2}}{8 g} \\
& \cdot\left\{1+1.032 \frac{\left(\omega_{P}+\omega_{r}\right)^{2} / \omega_{\text {lal }}^{2}}{\left|1-\left(\omega_{P}+\omega_{r}\right)^{2} / \omega_{\text {lal }}^{2}\right| \pm\left(\mathrm{PL}_{1}^{2} / \pi^{2} \mathrm{EI}\right)}\right\},
\end{aligned}
$$

where $\omega_{\mathrm{lal}}$ is the natural frequency of drillstring, $\omega_{\text {lal }}=\sqrt{\mathrm{EI} \pi^{4} / \rho \mathrm{AL}_{1}^{4}}$, and $\rho$ is the drilling tool density.

The expression for the bending stress $\sigma_{w}$ is given by

$$
\begin{aligned}
\sigma_{w}= & \frac{\gamma_{s} \cdot A \cdot R \cdot \omega_{P}^{2} \cdot L_{1}^{2}}{8 g(I / C)} \\
& \cdot\left\{1+1.032 \frac{\left(\omega_{P}+\omega_{r}\right)^{2} / \omega_{\text {lal }}^{2}}{\left|1-\left(\omega_{P}+\omega_{r}\right)^{2} / \omega_{\text {lal }}^{2}\right| \pm\left(P L_{1}^{2} / \pi^{2} E I\right)}\right\} .
\end{aligned}
$$

The expression for $I / C$ is given as $I / C=\pi D_{o}^{3}\left(1-\theta^{4}\right) / 32$, and $\theta$ can be obtained by $\theta=D_{i} / D_{o}$.

2.3. Fatigue Safety Factor Model. The drillstring is affected by alternating stress during drilling. Alternating stress 


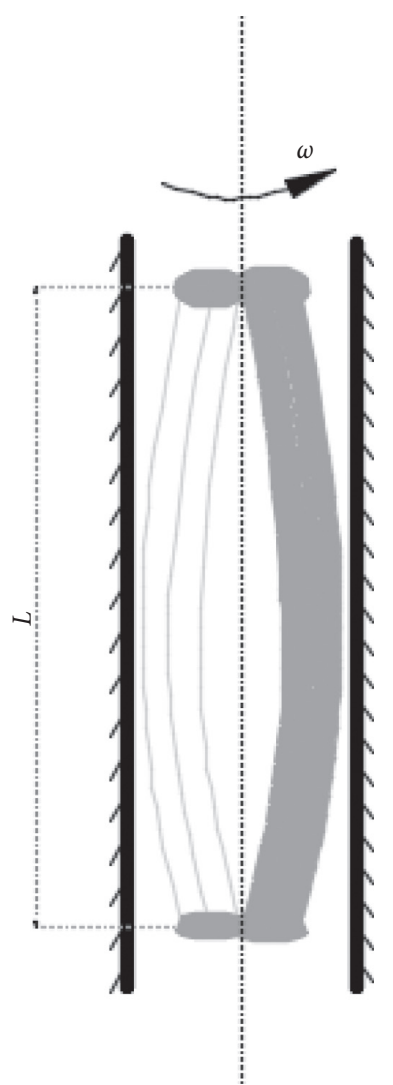

(a)

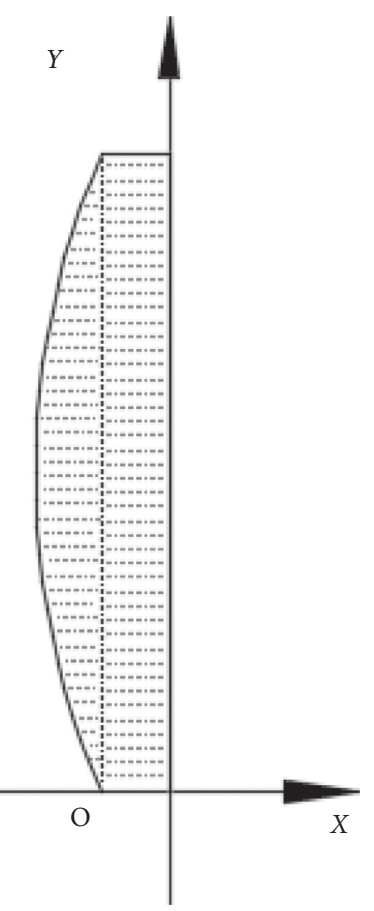

(b)

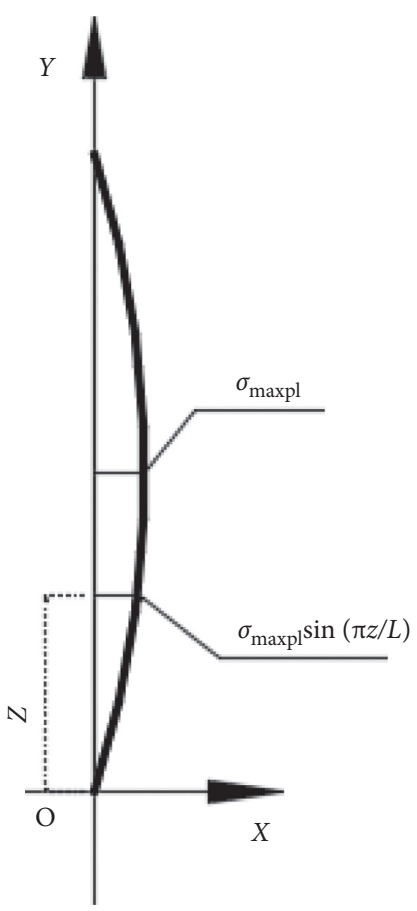

(c)

Figure 2: (a) Schematic diagram of drillstring whirl. (b) Schematic diagram of stress distribution. (c) Schematic diagram of strain.

leads to fatigue of metal, and drillstring tensile strength is reduced, which can easily cause fatigue failure. Lateral vibration can decrease quickly the fatigue life of drilling tool. In the case of whirling, the drillstring bears axial pressure, bending moment, torque, and hydraulic pressure.

The alternating stress causes metal fatigue of the drill pipe, and its tensile strength decreases, which makes the drill tool prone to fatigue failure.

2.3.1. Axial Stress. The axial stress of drillstring is composed of gravity, WOB, and so forth. The effective axial stress at any axial section is as follows.

The axial load $F_{a}$ is determined via the following equation:

$$
F_{a}=L q_{\mathrm{sm}}-P,
$$

where $L$ is the distance from section to bottom hole, $P$ represents the WOB, and $q_{s m}$ can be expressed as $q_{\mathrm{sm}}=\gamma_{s} K_{f} ; K_{f}$ is the buoyancy factor, and $\gamma_{s}$ represents weight per unit length of drill pipe, so computational equations of axial stress are given as follows:

$$
\sigma_{a e}=\frac{L \cdot \gamma_{s} \cdot K_{f}-P}{A} .
$$

2.3.2. Bending Stress. The bending stress caused by backward whirling of drilling tool can be calculated by equation (6).

2.3.3. Shear Stress. During the drilling process, the rotary table transmits the torque to the drill bit through the drillstring, so there are shear stresses on each cross section of the drillstring. The equations for calculating torque $M$ and shear stress $\tau_{\text {mo }}$ are as follows [31]:

$$
\begin{aligned}
M & =\frac{9549 \cdot N}{n}=\frac{9549 \cdot\left(N_{s}+N_{b}\right)}{n}, \\
\tau_{\text {mo }} & =\frac{16 M \cdot D_{o}}{\pi\left(D_{o}^{4}-D_{i}^{4}\right)},
\end{aligned}
$$

where $n$ is the RPM, $N_{s}$ represents power required for drillstring rotation $(n<230 \mathrm{rpm})$, and $N_{b}$ is the power of bit for breaking rock (roller bit).

2.3.4. Circumferential Stress $\sigma_{t}$ and Radial Stress $\sigma_{r}$. The radial and circumferential stresses on any cross section of the drilling tool under the internal and external pressure of the drilling fluid can be calculated by Lame equation: 


$$
\begin{gathered}
\sigma_{r}=\frac{D_{o}^{2} P_{o}-D_{i}^{2} P_{i}}{D_{o}^{2}-D_{i}^{2}}-\frac{D_{o}^{2} D_{i}^{2}\left(P_{o}-P_{i}\right)}{D^{2}\left(D_{o}^{2}-D_{i}^{2}\right)}, \\
\sigma_{t}=\frac{D_{o}^{2} P_{o}-D_{i}^{2} P_{i}}{D_{o}^{2}-D_{i}^{2}}+\frac{D_{o}^{2} D_{i}^{2}\left(P_{o}-P_{i}\right)}{D^{2}\left(D_{o}^{2}-D_{i}^{2}\right)} .
\end{gathered}
$$

2.3.5. The Calculation of Stress Synthesis and Safety Factor. According to the fourth strength theory, the equivalent stress can be obtained:

$$
\begin{gathered}
\sigma_{e \max }=\sqrt{\frac{1}{2}\left(\left(\sigma_{a e}+\sigma_{w}-\sigma_{r}\right)^{2}+\left(\sigma_{r}-\sigma_{t}\right)^{2}+\left(\sigma_{t}-\sigma_{a e}-\sigma_{w}\right)^{2}\right)}, \\
\sigma_{e \min }=\sqrt{\frac{1}{2}\left(\left(\sigma_{a e}-\sigma_{w}-\sigma_{r}\right)^{2}+\left(\sigma_{r}-\sigma_{t}\right)^{2}+\left(\sigma_{t}-\sigma_{a e}+\sigma_{w}\right)^{2}\right)} .
\end{gathered}
$$

Taking the shear stress into account, the equivalent stress is

$$
\begin{aligned}
& \sigma_{\text {eq } \min }=\sqrt{\sigma_{e \min }^{2}+3 \tau_{\max }^{2}} \\
& \sigma_{\text {eq } \max }=\sqrt{\sigma_{e \max }^{2}+3 \tau_{\max }^{2}}
\end{aligned}
$$

Therefore, the average stress and stress amplitude can be obtained by the following equations:

$$
\begin{gathered}
\sigma_{m}=\frac{1}{2}\left(\sigma_{\text {eq } \max }+\sigma_{\text {eq min }}\right), \\
\sigma_{a}=\frac{1}{2}\left(\sigma_{\text {eq } \max }-\sigma_{\text {eq min }}\right) .
\end{gathered}
$$

The computational equation of safety factor is given as follows:

$$
n_{\sigma}=\frac{\sigma_{-1}}{\sigma_{a}+\psi_{\sigma} \cdot \sigma_{m}},
$$

where $\psi_{\sigma}$ is a coefficient related to the material. The fatigue strength limit of the drillstring under corrosive conditions is approximately $\sigma_{-1}=0.1275 \sigma_{b}+10.5$ [32].

\section{Simulation Parameters}

(1) Actual data (Table 1) was used for the whirl state of the drillstring simulation analysis and determining the trajectory and velocity of point $P$ when the drill whirls.

(2) By using drill tool assembly parameters, we calculated the force and safety factor of the drill tool under different conditions and analyzed the influence of stress on the safety factor of the drill tool. The following table (Table 2) shows the parameters of drill tool assembly. We studied the force and safety of these two groups of drill tool assemblies and analyzed the impact of different stresses on safety of drillstring.

\section{Results}

4.1. Whirl of Drilling Tools. When the drilling tool is backward whirling without sliding, the RPM of the drilling tool is adjusted to analyze the influence of the outer diameter of the drillstring (Table 1) on the whirl angular speed. It can be seen from Figure 3 that the greater the speed is and the larger the diameter of the drilling tool is, the more intense the whirl of the drilling tool is.

From Figure 3, it can be seen that angular velocity of backward whirling changes with diameter of drillstring. At a well diameter of $190.5 \mathrm{~mm}$ and a drill pipe diameter of $139.7 \mathrm{~mm}$, the trajectory of the $P$-point of the drilling tool was analyzed over time. As shown in Figure 4, the bigger the PRM values, the higher the frequency of point $P$ contacting the borehole wall. The frequency of stress changes in the drill tool will also be greater, which will make the drill tool more vulnerable to damage.

Figure 5 shows the variation of velocity of point $P$. The higher the RPM, the faster speed change frequency of point $P$, and the velocity of point $P$ is also significantly higher. The reason for the rapid change of velocity is that point $P$ is in contact with the well wall and the stress is changed greatly.

4.2. Bending Stress. Whirl is one of the main factors affecting the safety of drilling tools, and the bending stress produced by whirling has a great influence on the safety of drilling tools. In this section, two examples are used to analyze the bending stress of drilling tool during whirling under different conditions.

4.2.1. Case 1. The bending stress of drillstring whirling is calculated by using the data of example 1 in simulation parameters (Table 2) and the bending stress model of drillstring in case of whirling.

Figure 6 shows the bending stress of the drilling tool when the RPM is $80 \mathrm{rpm}$ and the WOB is $80 \mathrm{kN}$. It can be seen from Figure 6 that the bending stress of different parts of the drilling tool is different. The bending stress on the upper part of the drilling tool is smaller than that of the bottom part. The upper part of the drill tool is subjected to greater axial stress due to the weight of the drill tool, and the degree of whirl is lower, so the bending stress on this part is smaller. The bottom of drilling tool whirls violently, and the axial force is small, so the bending stress is large. Figure 7 shows the bending stress variation of dangerous point $A$ (near the connection point of HWDP and DC) under the conditions of $\mathrm{WOB}=60-160 \mathrm{kN}$ and $\mathrm{RPM}=40-150 \mathrm{rpm}$.

According to Figure 7, it can be seen that the bending stress of point $A$ increases with the increase of the RPM of the drill. When the RPM of the drill reaches around $80 \mathrm{rpm}$, the bending stress of the drill reaches its peak. The bending stress on point $A$ generally increases with the increase of RPM and WOB, and the WOB has a low degree of influence on the bending stress of the drilling tool.

4.2.2. Case 2. The bending stress of the dangerous point of the drilling tool is calculated by using the relevant 
TABLe 1: Parameters of speed of rotation, well diameter, and drilling tool.

\begin{tabular}{lc}
\hline Speed of rotation & $\omega_{1}=30 \mathrm{rpm}, \omega_{2}=60 \mathrm{rpm}, \omega_{3}=120 \mathrm{rpm}$ \\
\hline Parameter 1 $(\mathrm{mm})$ & $D_{w}=190.5, D_{O}=60.3,73.02,88.9,101.6,114.3,127,139.7,149.2$ \\
Parameter 2 $(\mathrm{mm})$ & $D_{w}=269.9, D_{O}=88.9,101.6,114.3,127,139.7,149.2,177.8,203.2$ \\
\hline
\end{tabular}

TABle 2: Parameters of drilling tool assembly.

\begin{tabular}{|c|c|c|}
\hline \multirow{2}{*}{ Drill parameters } & \multicolumn{2}{|c|}{ Drill tool assembly } \\
\hline & Example 1 (length: 7294 m) & Example 2 (length: $6461 \mathrm{~m}$ ) \\
\hline Drill pipe 1 & $127 \mathrm{~mm} \mathrm{DP} \times 3335 \mathrm{~m}$ & $139.7 \mathrm{~mm} \mathrm{DP} \times 3119 \mathrm{~m}$ \\
\hline Drill pipe 2 & $101.6 \mathrm{~mm} \mathrm{DP} \times 3500 \mathrm{~m}$ & $127 \mathrm{~mm} \mathrm{DP} \times 3000 \mathrm{~m}$ \\
\hline HWDP & $127 \mathrm{~mm}$ HWDP $\times 135 \mathrm{~m}$ & $127 \mathrm{~mm}$ HWDP $\times 135 \mathrm{~m}$ \\
\hline Drill collar 1 & $139.7 \mathrm{~mm} \mathrm{DC} \times 324 \mathrm{~m}$ & $177.8 \mathrm{~mm} \mathrm{DC} \times 153 \mathrm{~m}$ \\
\hline Drill collar 2 & & $203.2 \mathrm{~mm} \mathrm{DC} \times 54 \mathrm{~m}$ \\
\hline Drill bit & $190.5 \mathrm{~mm}$ & $269.9 \mathrm{~mm}$ \\
\hline WOB & $60-160 \mathrm{kN}$ & $60-160 \mathrm{kN}$ \\
\hline $\mathrm{RPM}$ & $40-150 \mathrm{rpm}$ & $40-150 \mathrm{rpm}$ \\
\hline Drilling fluid density & $1.65 \mathrm{~g} / \mathrm{cm}^{3}$ & $1.35 \mathrm{~g} / \mathrm{cm}^{3}$ \\
\hline
\end{tabular}
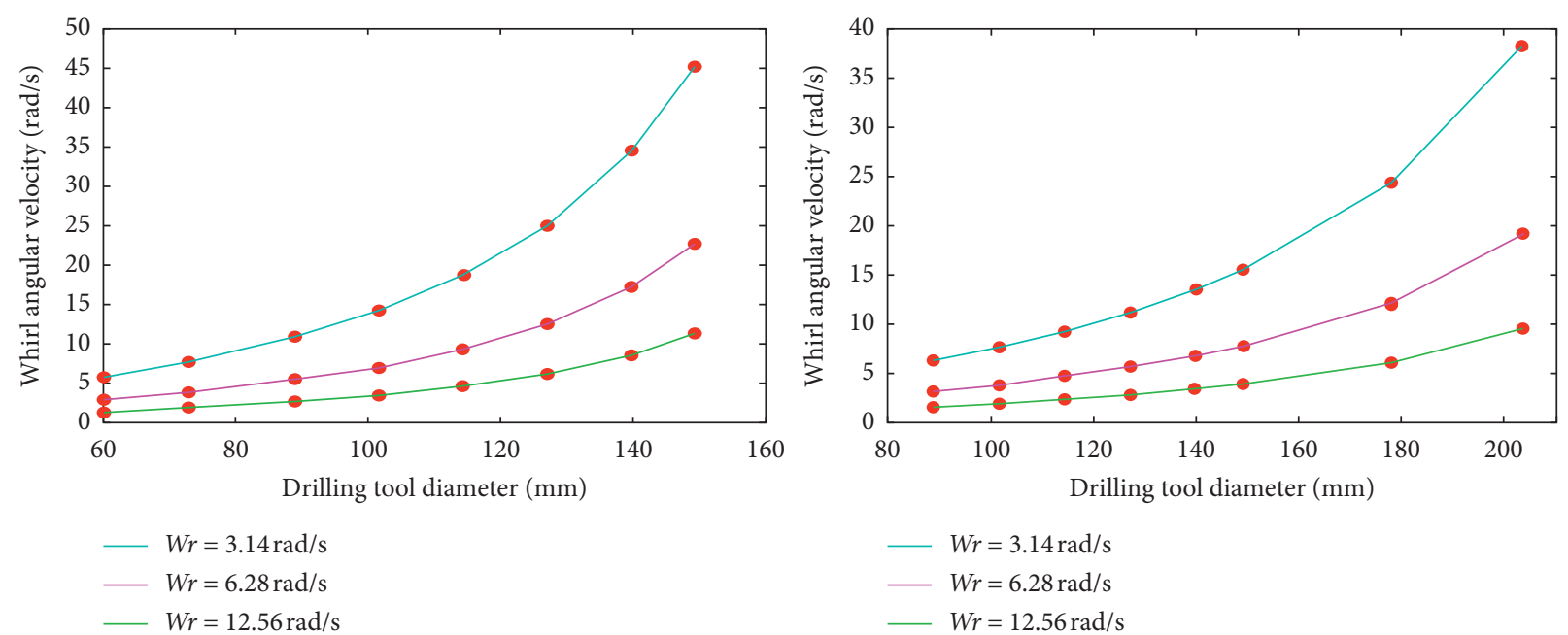

FIGURE 3: Angular velocity of backward whirling changes with drilling tool diameter (RPM=30, 60, and $120 \mathrm{rpm})$.
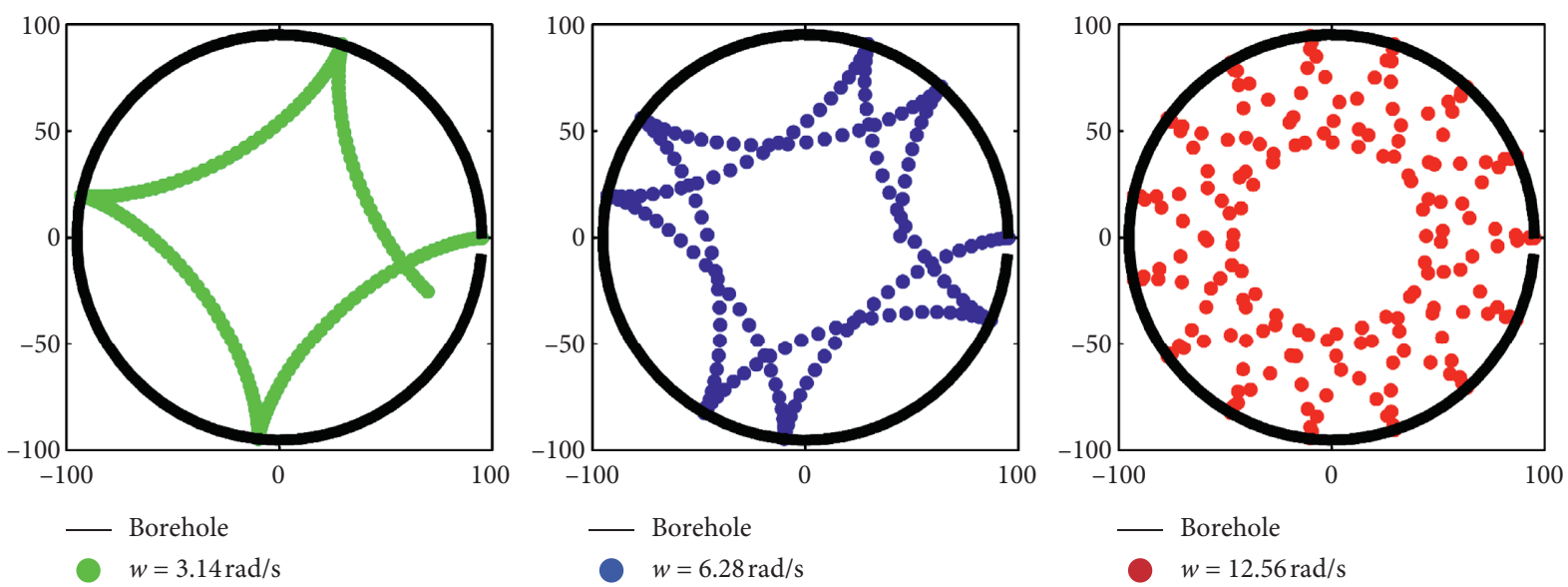

FIgURE 4: Schematic diagram of $P$-point trajectory when time $t=1-2 \mathrm{~s}$. 

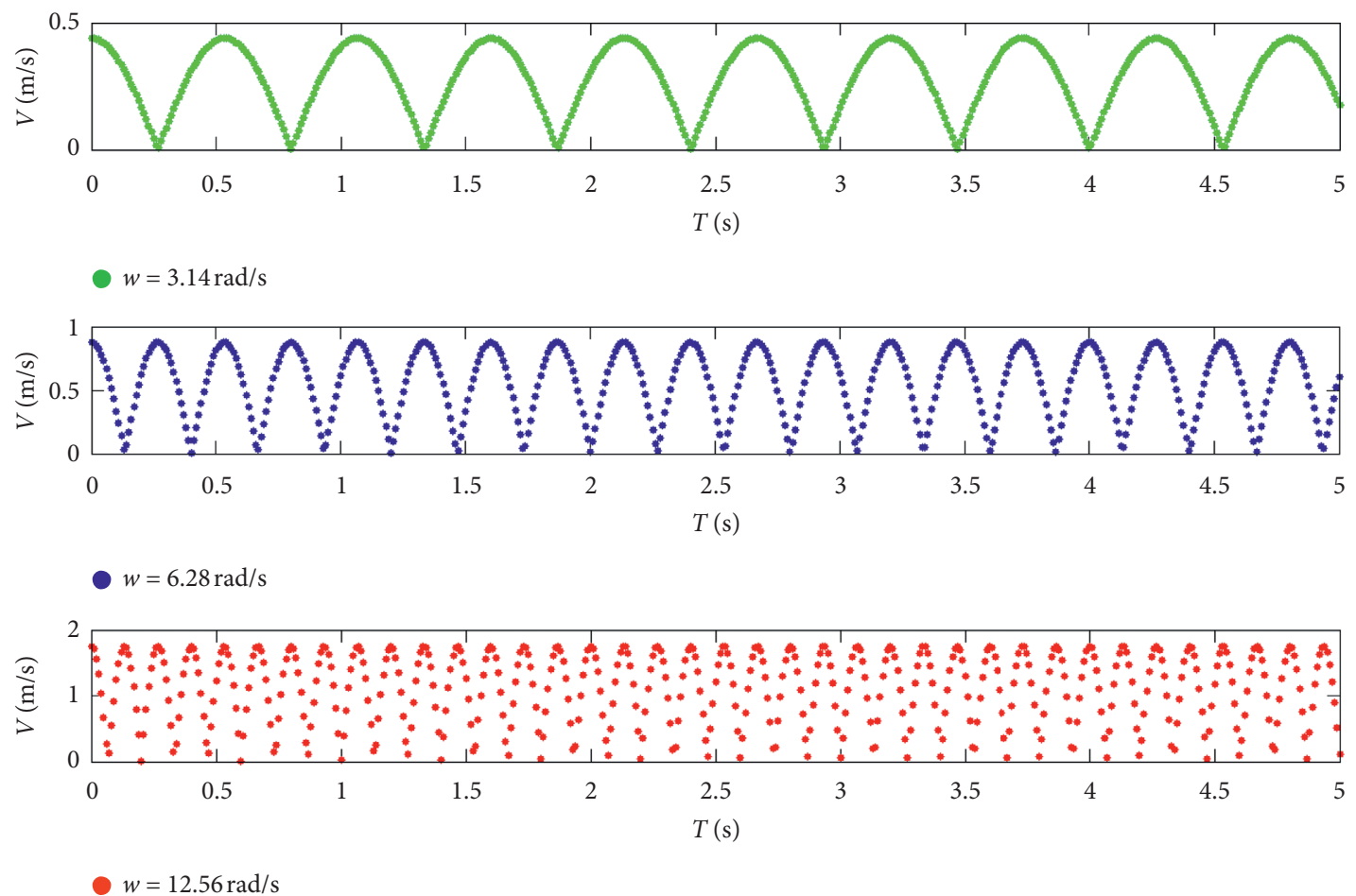

FIgURE 5: Schematic diagram of the change in velocity of point $P$ when time $t=1-5 \mathrm{~s}$.

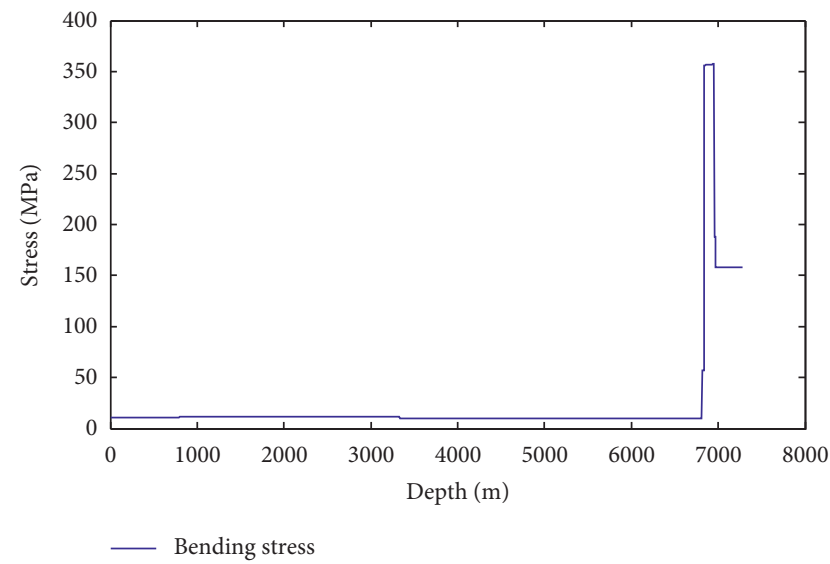

FIGURE 6: Variation of bending stress with distance from section to wellhead.

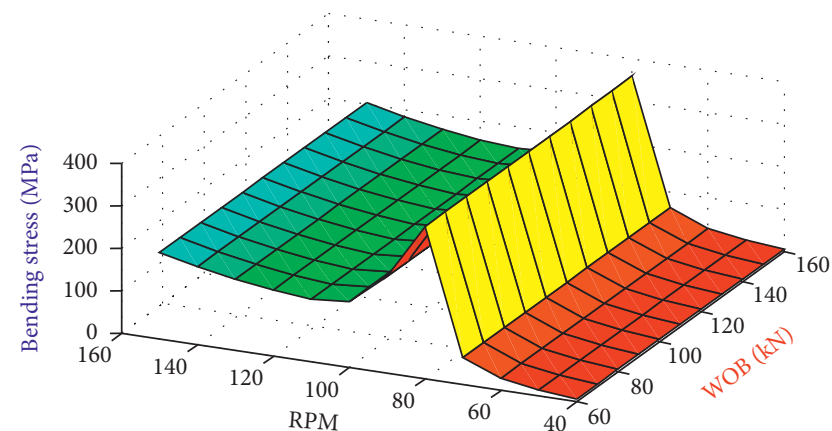

Figure 7: Schematic diagram of RPM-WOB-bending stress. parameters of example 2 (Table 2 ) in the simulation parameters. This point $B$ is located near the connection between the heavy weight drill pipe and the drill collar. The figure below shows a schematic diagram of the bending stress of point $B$ under the different WOB and RPM (WOB: 60-160 kN; RPM: 40-150 rpm).

According to Figure 8, the bending stress will increase with the increase of $\mathrm{WOB}$, and the overall trend of bending stress of drilling tool will increase with the increase of RPM. When the RPM reaches $90 \mathrm{rpm}$, the bending stress of the drilling tool reaches its peak value (a small range). When the RPM exceeds $100 \mathrm{rpm}$, the bending stress of the drilling tool still increases with the increase of the RPM.

It can be seen from Figures 7 and 8 that, with the increase of the RPM and WOB of the drilling tool, the bending stress of the dangerous point will increase. The influence of WOB and RPM on bending stress is different. The change of the RPM has higher influence than the WOB of drilling tool on bending stress.

\subsection{Fatigue Safety Factor}

4.3.1. Case 1. According to equations (11)-(14), the fatigue strength checking program of drilling tool is compiled to check drilling tool strength.

Through this program, the fatigue strength of drill pipe can be analyzed. The program is used to analyze example 1 (Table 2), and we obtain the stress diagram and fatigue safety factor diagram of drilling tool.

According to Figure 9(a), it can be known that the axial stress of the drilling tool decreases as the depth increases. This is 


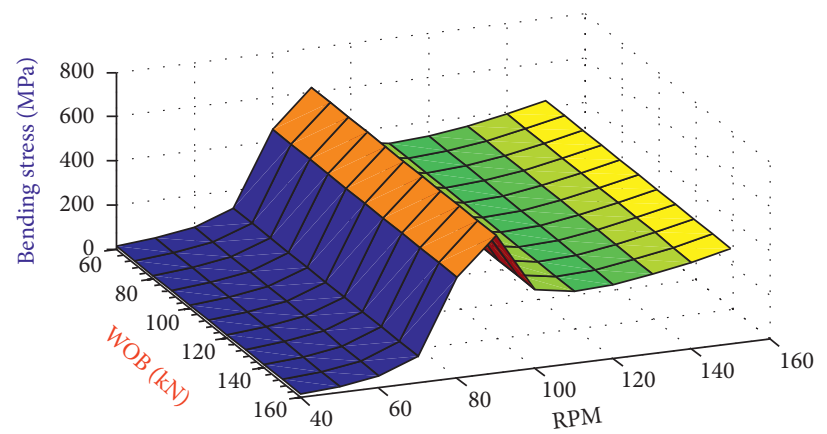

FIgURE 8: Schematic diagram of RPM-WOB-bending stress.

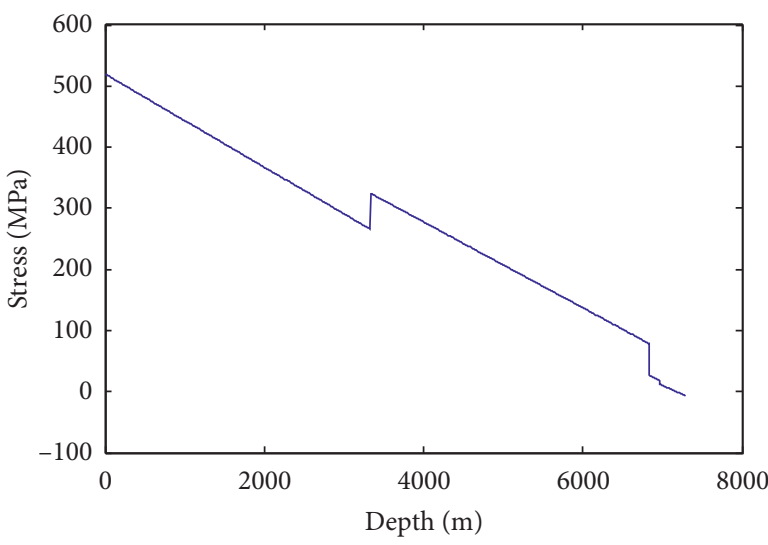

— Axial stress

(a)

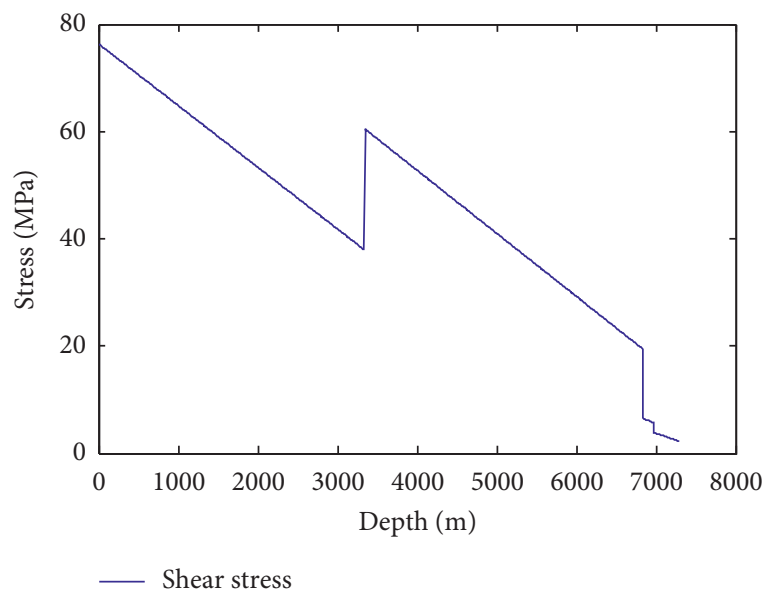

(c)

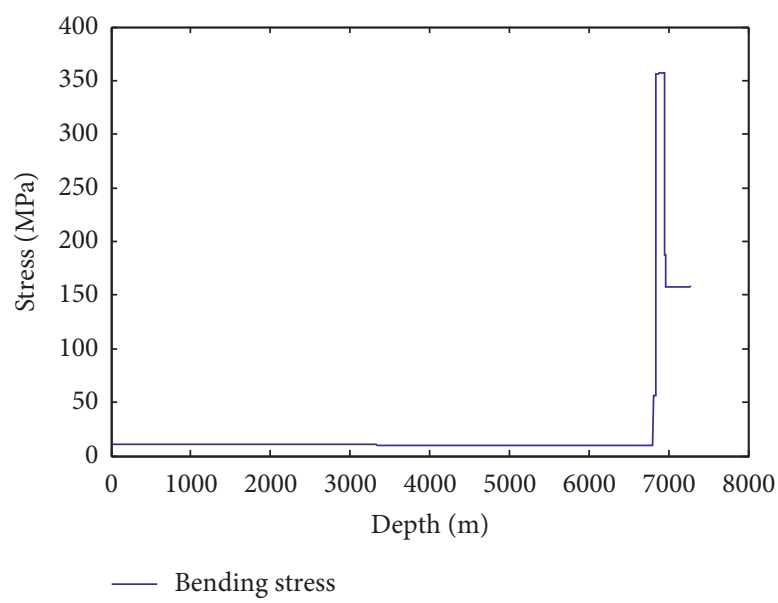

(b)

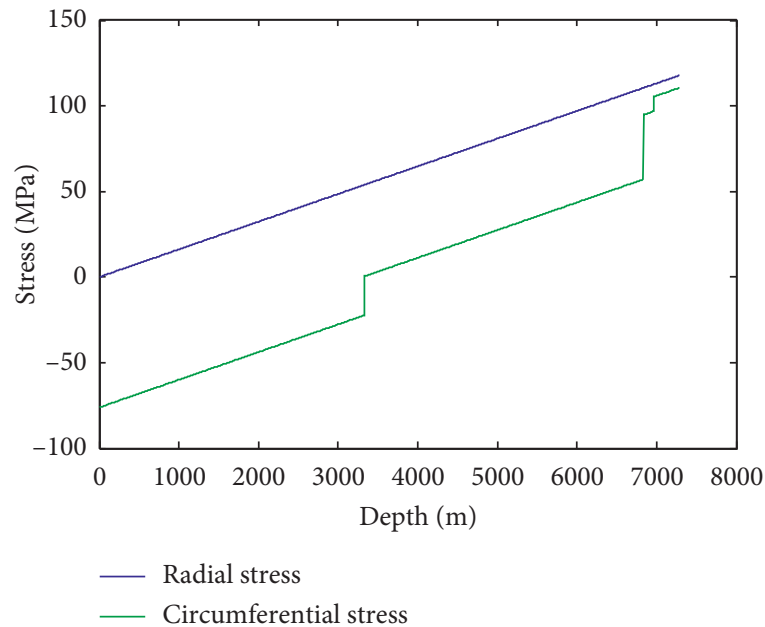

(d)

Figure 9: Schematic diagram of stress changing with distance from section to wellhead. (a) Change of axial stress. (b) Change of bending stress. (c) Change of shear stress. (d) Change of circumferential stress and radial stress.

because as the depth of the well increases, the length of the drill pipe under the section decreases, and the axial load decreases on the section. According to equation (6), bending stress of drilling tool is related to axial pressure, RPM, and properties of drilling tool. According to Figure 9(b), it is shown that when the RPM is $80 \mathrm{rpm}$, the bending stress reaches maximum on the weighted drill pipe. Figure 9(c) shows that the shear stress on the cross section of the drilling tool decreases with the increase of depth. Figure 9(d) shows that the radial stress of drilling tool increases with the increase of well depth. The circumferential stress decreases firstly and then increases with the increase of well depth.

According to equation (14), we can obtain the fatigue safety factor curve of drilling tool. According to the analysis of Figure 10, it is found that the fatigue safety factor is low in the location of the wellhead, weighted drill pipe, and drill 


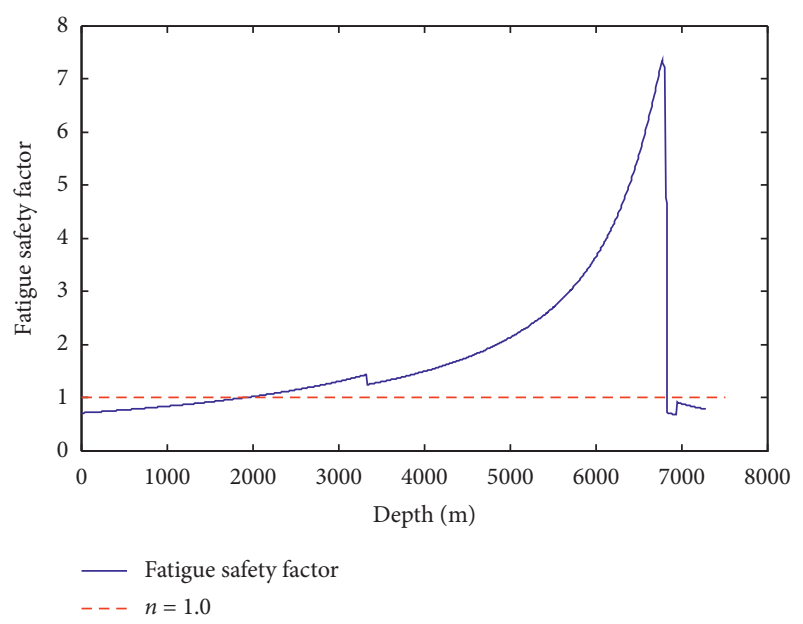

(a)

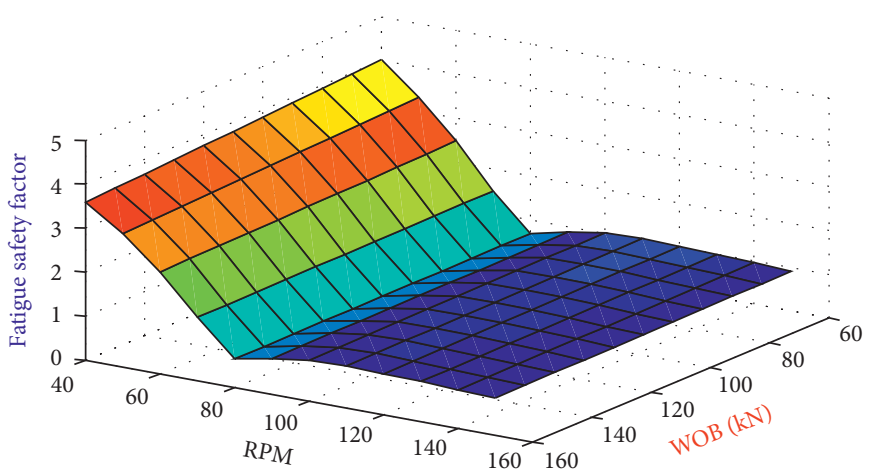

(b)

Figure 10: (a) Safety factor diagram of drilling tool. (b) Safety factor of connection point between weighted drill pipe and drill collar (WOB: 60-160 kN; RPM: 40-150 rpm).

collar, and there is a risk of fatigue failure during drilling. The safety factor is small at the wellhead position of the drilling tool because of the influence of axial stress, shear stress, and circumferential stress. The main reason for the lower fatigue safety factor in the location of the weighted drill pipe and drill collar position is the influence of great bending stress, radial stress, and circumferential stress of the drill tool.

According to the analysis of Figures 9 and 10, it is found that the axial stress and bending stress have great influence on the safety factor of drilling tool.

There is a negative correlation between the safety factor and the overall change trend of the axial stress of the upper drilling tool. The safety factor of the bottom hole drilling tool is closely related to the bending stress of the drilling tool, and the change trend of the safety factor is basically opposite to that of the bending stress. When the drill tool assembly is fixed, the safety factor of drilling tool is closely related to WOB and RPM.

4.3.2. Case 2. In order to explore the correlation between the drilling state of drilling tools and the safety factor of drilling tools, another relevant example 2 is selected for analysis. According to the calculation, the dangerous point of drilling tool is near the joint of $127 \mathrm{~mm}$ weighted drill pipe and $177.8 \mathrm{~mm}$ drill collar. The schematic diagram of the change of safety factor with WOB and RPM is shown below.

From Figure 11, it can be seen that the safety factor of this point decreases with the increase of WOB and RPM. The figure shows that when the RPM is less than $70 \mathrm{rpm}$, the safety factor of the drill is greater than 1 . The fatigue safety factor is less than 1 when the RPM is higher than $70 \mathrm{rpm}$, and the fatigue safety factor of drilling tool is the smallest when the RPM is $90 \mathrm{rpm}$.
4.4. The Relationship between Stress and Fatigue Factor. The change of safety factor is due to the change of stress on drilling tool, so it is necessary to analyze the influence of stress on safety factor. RPM and WOB are the main factors affecting the safety factor and the stress of drilling tools. Therefore, we can adjust the WOB and RPM of the drilling tool to determine the change of the stress and the magnitude of the stress, so as to judge the relationship between the stress and the fatigue safety factor of the drilling tool.

It can be seen from Figure 12(a) that the axial stress decreases with the increase of WOB; Figure 12(b) shows that the shear stress increases with the increase of WOB. The axial stress and shear stress have little effect on the safety factor of drilling tools.

The change of WOB has little effect on the axial stress and shear stress of the drilling tool, and the circumferential stress and radial stress are not affected. The change of WOB and RPM has great influence on the bending stress of drilling tools. Therefore, it can be assumed that the bending stress is the main factor causing the change of fatigue safety factor of drilling tool. The changes of bending stress and fatigue safety factor can be seen from Figure 13 .

Analyzing the dangerous point $A$ in example 1 , it is found that when the RPM is about $80 \mathrm{rpm}$, the bending stress on this point is the largest, and the safety factor is the smallest. Generally speaking, the changing trend of bending stress is opposite to that of safety factor.

Analyzing the dangerous point $B$ in example 2, it is found that when the RPM of the drilling tool is about $90 \mathrm{rpm}$, the bending stress reaches the maximum and the safety factor is the minimum. From Figure 14, it can be found that the change trend of the bending stress and the change trend of the safety factor are also opposite.

Therefore, it can be concluded that the fatigue safety factor is closely related to the whirl degree of drilling tools, 


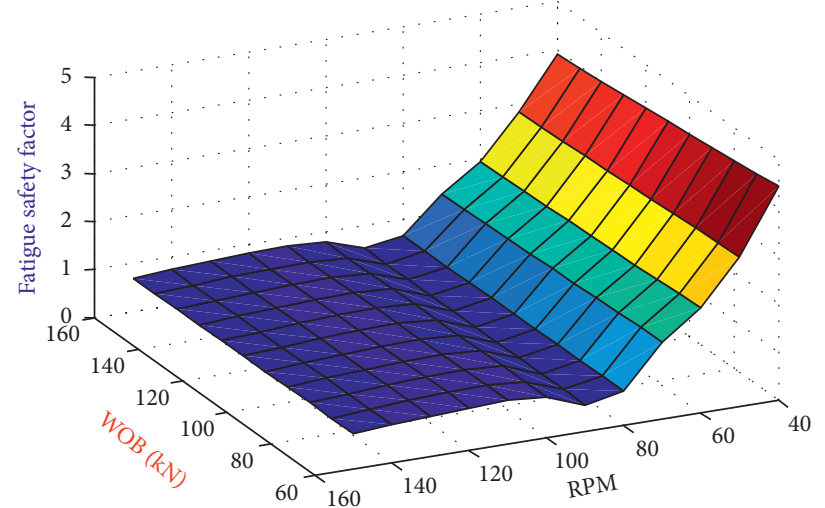

FIGURE 11: RPM-WOB-safety factor diagram of drilling tool (WOB: 60-160 kN; RPM: 40-150 rpm).

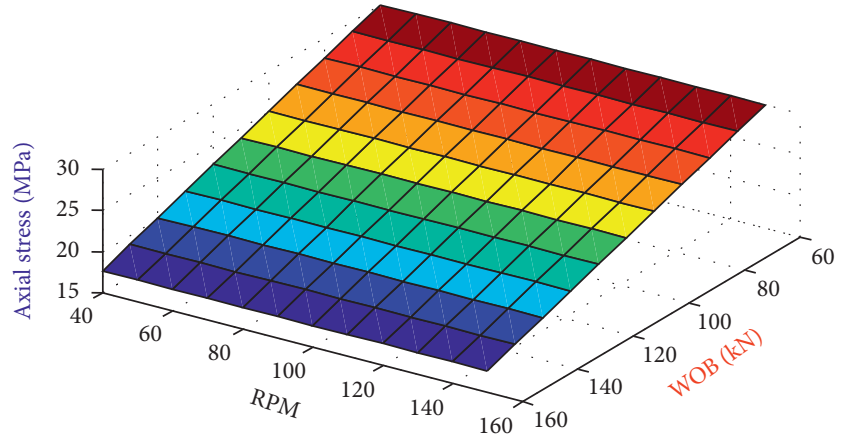

(a)

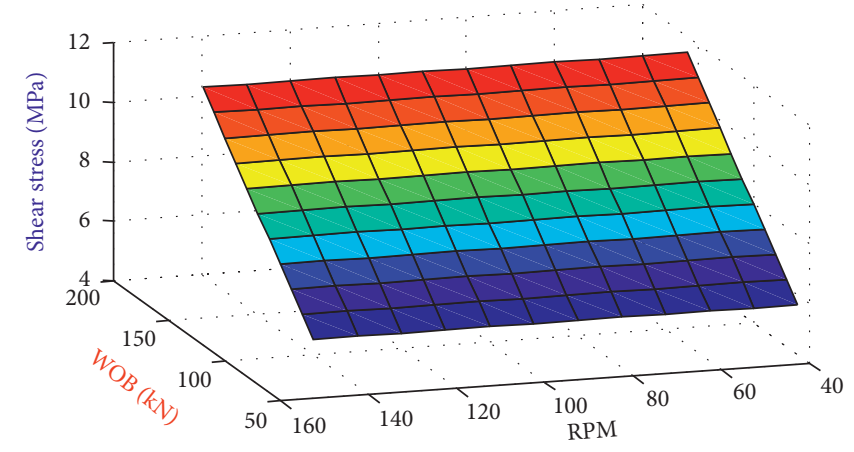

(b)

Figure 12: (a) Schematic diagram of axial stress change. (b) Schematic diagram of shear stress change (point $B$ of example 2, WOB: 60-160 $\mathrm{kN}$ and RPM: 40-150 rpm).

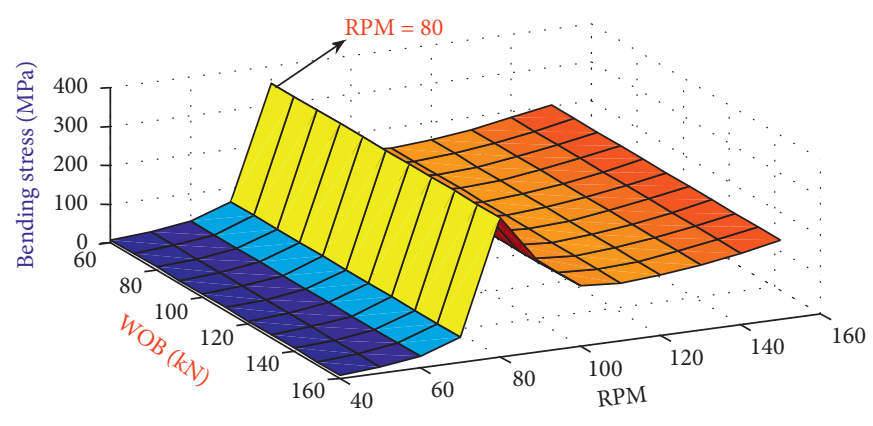

(a)

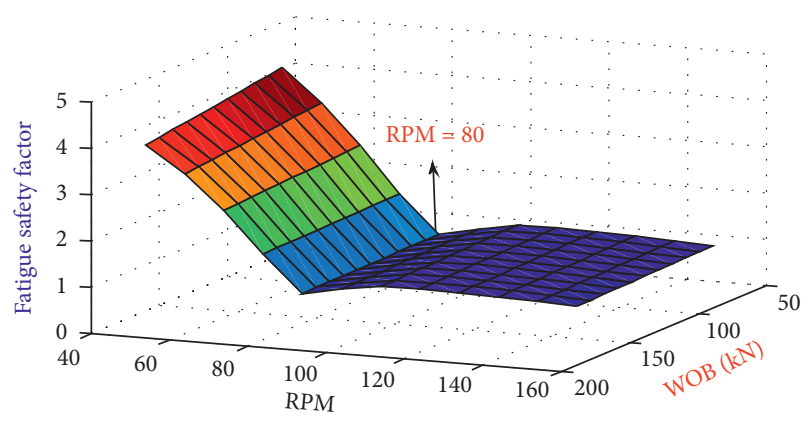

(b)

Figure 13: (a) Diagram of bending stress of point $A$. (b) Diagram of fatigue safety factor of point $A$.

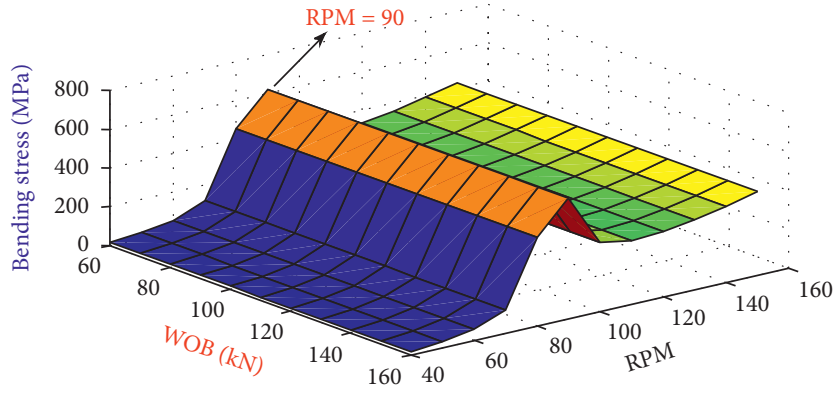

(a)

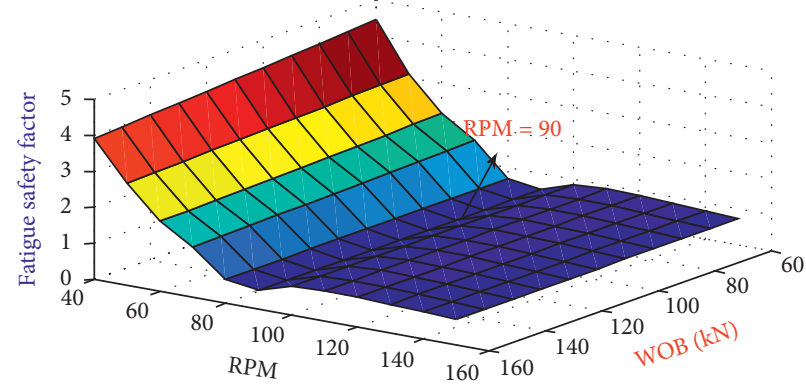

(b)

Figure 14: (a) Diagram of bending stress of point $B$. (b) Diagram of fatigue safety factor of point $B$. 
and the bending stress has great influence on the safety factor of drilling tools.

\section{Conclusions}

Based on the analysis of various factors, such as the whirling characteristics, the stress conditions, the calculation method of fatigue safety factor, and drilling conditions, the following conclusions can be drawn:

(1) Through the research on the whirl characteristics of the drilling tool and the analysis of the trajectory of point $P$ under different RPM $(30 \mathrm{rpm}, 60 \mathrm{rpm}$, and $120 \mathrm{rpm})$, it is found that the contact frequency is greater between point $P$ and the borehole wall when the RPM is $120 \mathrm{rpm}$. With the increase of RPM, the degree of drilling tools backward whirl is more intense, the frequency of alternating stress changes increases, and the fatigue life of drilling tool will be reduced.

(2) With the increase of RPM, the bending stress of dangerous points increases and the fatigue safety factor decreases. With the increase of WOB, the bending stress of dangerous points increases slightly and the safety factor decreases. It is shown that the RPM has a greater influence on the safety of drilling tools (RPM: 40-150 rpm; WOB: $60-160 \mathrm{kN}$ ).

(3) The variation trend of fatigue safety factor is opposite to that of bending stress caused by whirl of drilling tool. Therefore, the whirling degree should be considered greatly in the process of drilling tool design, and the RPM of the drilling tool should be selected reasonably in drilling engineering.

(4) The downhole vibration of drilling tools is the result of coupling of various vibration modes, and the change of the alternating stress is extremely complex. Therefore, if we need to further analyze the fatigue safety of drilling tools, it is necessary to combine with actual drilling conditions and consider the impact of vibration to drilling tools.

\section{Data Availability}

The data in the tables used to support the findings of this study are included within the article. The data in the figures used to support the findings of this study are available from the corresponding author (wdlc282@163.com) upon request.

\section{Conflicts of Interest}

The authors declare that they have no conflicts of interest.

\section{Acknowledgments}

This study was supported by the National Natural Science Foundation of China (51704264 and 42072341) and Fundamental Research Funds for the Central Universities (2-92018-096).

\section{References}

[1] A. Baryshnikov, A. Calderoni, A. Ligrone, and P. Ferrara, "A new approach to the analysis of drillstring fatigue behavior," SPE Drilling \& Completion, vol. 12, no. 2, 1997.

[2] Y. Shen, Z. Zhang, J. Zhao et al., "The origin and mechanism of severe stick-slip," in Proceedings of the SPE Annual Technical Conference and Exhibition, San Antonio, TX, USA, October 2017.

[3] Y. Liu, F. Li, X. Xu, B. Yang, and C. Lu, "Simulation technology in failure analysis of drill pipe," Procedia Engineering, vol. 12, pp. 236-241, 2011.

[4] B. Adam, R. Harmer, J. Sugiura et al., "Continuous highfrequency measurements of the drilling process provide new insights into drilling-system response and transitions between vibration modes," SPE Drilling \& Completion, vol. 31, no. 2, 2016.

[5] K. A. Macdonald and J. V. Bjune, "Failure analysis of drillstrings," Engineering Failure Analysis, vol. 14, no. 8, pp. 1641-1666, 2007.

[6] M. T. Albdiry and M. F. Almensory, "Failure analysis of drillstring in petroleum industry: a review," Engineering Failure Analysis, vol. 65, pp. pp74-85, 2016.

[7] K. K. Millheim and M. C. Apostal, "The effect of bottomhole assembly dynamics on the trajectory of a bit," Journal of Petroleum Technology, vol. 33, no. 12, pp. 2323-2338, 1981.

[8] W. R. Tucker and C. Wang, "An integrated model for drillstring dynamics," Journal of Sound and Vibration, vol. 224, no. 1, pp. 123-165, 1999.

[9] M. J. Knight and F. P. Brennan, "Fatigue life improvement of drill collars through control of bore eccentricity," Engineering Failure Analysis, vol. 6, no. 5, pp. 301-319, 1999.

[10] R.-h. Wang, Y.-b. Zang, R. Zhang, Y.-h. Bu, and H.-z. Li, "Drillstring failure analysis and its prevention in northeast Sichuan, China," Engineering Failure Analysis, vol. 18, no. 4, pp. 1233-1241, 2011.

[11] W. C. Chin, "Drillstring vibrations: classic ideas and modern approaches," Wave Propagation in Drilling, Well Logging and Reservoir Applications, Wiley, Hoboken, NJ, USA, pp. 109256, 2014.

[12] W. Jiang, "Drill-pipe bending and fatigue in rotary drilling of horizontal wells," in Proceedings of the SPE Eastern Regional Meeting, Columbus, OH, USA, October 1996.

[13] G. Heisig and M. Neubert, "Lateral drillstring vibrations in extended-reach wells," in Proceedings of the IADC/SPE Drilling Conference, New Orleans, LA, USA, February 2000.

[14] Q. Xue, H. Leung, L. Huang et al., "Modeling of torsional oscillation of drillstring dynamics," Nonlinear Dynamics, vol. 96, no. 1, pp. 267-283, 2019.

[15] F. Rajabali, H. Moradi, and G. Vossoughi, "Coupling analysis and control of axial and torsional vibrations in a horizontal drill string," Journal of Petroleum Science and Engineering, vol. 195, Article ID 107534, 2020.

[16] P. D. Spanos and A. M. Chevallier, "Oil well drilling: a vibration perspective," The Shock and Vibration Digest, vol. 35, pp. 81-99, 2003.

[17] R. F. Mitchell and M. B. Allen, "Lateral vibration: the key to BHA failure analysis," World Oil, vol. 200, no. 4, pp. 101-106, 1985.

[18] J. S. Mason and B. M. Sprawls, "Addressing BHA whirl: the culprit in mobile bay," SPE Drilling \& Completion, vol. 13, no. 4,1998

[19] D. A. Close, S. C. Owens, and J. D. Macpherson, "Measurement of BHA vibration using MWD," in Proceedings of 
the IADC/SPE Drilling Conference, Dallas, TX, USA, February 1988.

[20] S. C. Johnson, "A new method of producing laterally stable PDC drill bits,” SPE Drilling \& Completion, vol. 23, no. 3, pp. 314-324, 2008.

[21] A. Ghasemloonia, D. Geoff Rideout, and S. D. Butt, "Analysis of multi-mode nonlinear coupled axial-transverse drillstring vibration in vibration assisted rotary drilling," Journal of Petroleum Science and Engineering, vol. 116, pp. 36-49, 2014.

[22] L. Huang, Q. Xue, B. Liu et al., "Dynamic reliability analysis of rotary steering drilling system," Mechanical Sciences, vol. 10, no. 1, pp. 79-90, 2019.

[23] F. Poletto, J. M. Carcione, and G. Pinna, "Flexural waves in drill-string tubulars with variable loads," Geophysical Prospecting, vol. 61, no. 5, pp. 955-972, 2013.

[24] S. M. Sahebkar, M. R. Ghazavi, S. E. Khadem, and M. H. Ghayesh, "Nonlinear vibration analysis of an axially moving drillstring system with time dependent axial load and axial velocity in inclined well," Mechanism and Machine Theory, vol. 46, no. 5, pp. 743-760, 2011.

[25] K. J. Vandiver, J. W. Nicholson, and R.-J. Shyu, "Case studies of the bending vibration and whirling motion of drill collars," SPE Drilling Engineering, vol. 5, no. 4, pp. 282-290, 1990.

[26] H. Oueslati, A. Hohl, N. Makkar et al., "The need for high frequency vibration measurement along with dynamics modeling to understand the genesis of PDC bit damage," in Proceedings of the SPE-167993-MS, IADC/SPE Drilling Conference and Exhibition, Fort Worth, TX, USA, March 2014.

[27] Q. Zhu, Z. Zou, B. Huang, L. Ma, and J. Xia, "Downhole vibration causing a drill collar failure and solutions," Natural Gas Industry B, vol. 4, no. 2, pp. 73-80, 2017.

[28] D. R. H. Stroud, L. A. Lines, and D. J. Minett-Smith, "Analytical and experimental backward whirl simulations for rotary steerable bottom hole assemblies," in Proceedings of the SPE-140011-MS, IADC/SPE Drilling Conference and Exhibition, Amsterdam, Netherlands, March 2011.

[29] T. Popp, H. Stibbe, and D. Heinisch, "Backward whirl testing and modeling with realistic borehole contacts for enhanced drilling tool reliability," in Proceedings of the SPE-189600-MS, IADC/SPE Drilling Conference and Exhibition, Fort Worth, TX, USA, March 2018.

[30] Y. Zhang and Z. Xiao, "Lateral vibration and bending stress of a joint of drill pipe under self-excited whirlin," Society of Petroleum Engineers of AIME, SPE, pp. 1-13, 1992.

[31] G.-z. Zhao and W. Gong, Drilling Mechanics Foundation, pp. 101-118, Petroleum Industry Press, Beijing, China, 1988.

[32] X.-k. Zhang and Q.-f. Di, "Strength calculation of the whirled drillstring at flexural-torsional alternate stress," Natural Gas Industry, vol. 7, pp. 49-51, 2004. 